\title{
GULL PREDATION ON STOCKED TROUT FINGERLINGS
}

M. E. SWANSON, Fisheries and Wildlife Branch, Provincial Gov't. Bldg., Prince Albert, Sask.

The prairie aquaculture industry is confronted with many problems, among which is the early mortality of planted trout fingerlings. Scientists at the Freshwater Institute, Winnipeg, have suggested that bird predation is a major cause of this early season mortality.

On June 8, 1976, Ray Begrand, Paul Bashuk and I witnessed a spectacular case of gull predation on trout fingerlings. We were stocking a 20acre farm pond just west of Krydor, Saskatchewan, with 2,400 3-inch brown, brook and rainbow trout fingerlings ( 800 of each species) in the evening. We noted seven Franklin's Gulls along the bulrushes while we were releasing the fingerlings in midpond by boat.

The fish were transported to the stocking site in 12 cubitainers filled with water and oxygen. The fingerlings in two of the containers showed signs of stress from lack of oxygen and when released into the open water, some of them began spinning and jumping erratically at the surface. This activity seemed to attract the gulls, for within 5 minutes there were 30 birds hovering overhead and swooping down to pick up fish near the surface. On diving for fish, the gulls only dipped their head and necks below the water surface.

Our presence on the pond had no effect on their voracious feeding, which took place even within 20 feet of the boat. We went to shore and attempted to frighten away the birds by firing several rounds with a 22 -calibre rifle, but to no avail.

We followed the activity of one gull for a 10-minute period and counted 10

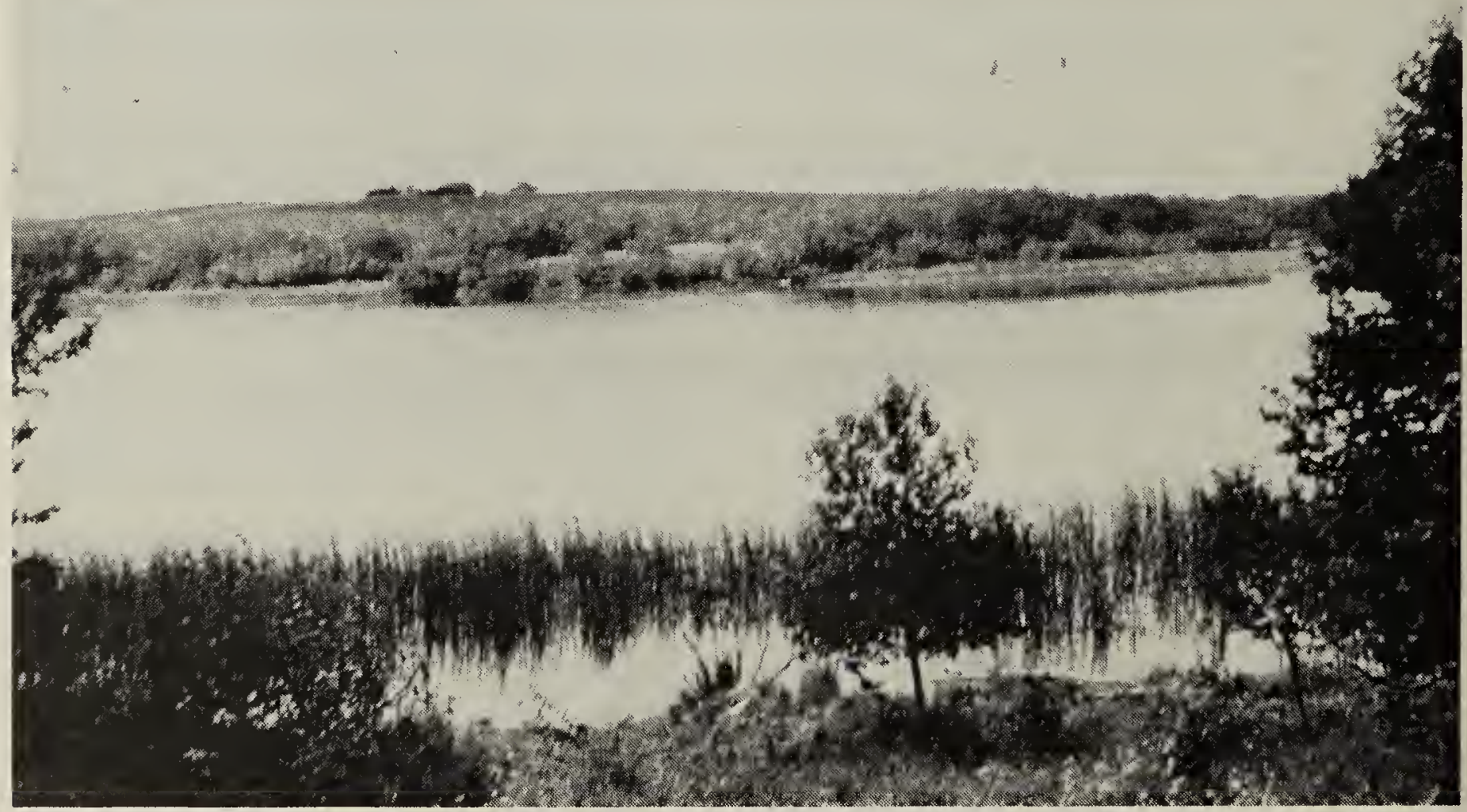

The dugout.

Paul Bashuk 
dives, at least eight of which were successful. This was after the gulls had already been feeding for about an hour; thus their prey was considerably less plentiful and their appetites must have been satiated somewhat by the time we took count. The flock of gulls conceivably devoured 700-800 fingerlings in the first hour after the fish were stocked, suggesting heavy mortality for the evening.

We stocked another 5 -acre pond just over the ridge from this pond with 600 fish (200 of each species) an hour earlier. There were nine gulls on the water when we stocked the fish, but they did not engage in active feeding as did the gulls on the first pond. All these fingerlings were in good condition going into the water and dispersed without any surface activity. Only occasionally did a gull dip below the surface, presumably feeding on aquatic invertebrates or fingerlings swimming by. The different behaviour of the birds on these two ponds suggests that the gulls were attracted by fingerlings spinning and jumping at the surface.

Trout fingerlings are particularly susceptible to predation shortly after stocking. Hatchery-reared trout possess inherent traits, such as surface response, schooling tendency, lack of wariness, and lack of foraging experience, which may place them at a definite disadvantage when they are required to make a rapid adjustment to conditions in the wild.' Research at the Freshwater Institute in 1975 has indicated that survival of trout was improved 30 to 40 percent by caging the fingerlings in the lake for two weeks prior to their release (pers. comm. Dr. G. B. Ayles).

'Vincent, R. E. 1960. Some influences of domestication upon three stocks of brook trout (Salvelinus fontinalis Mitchell). Trans. Amer. Fish. Soc. 89:35-52.

\section{SETTLEMENTS OF THE GRASSLANDS AND THE GREATER PRAIRIE CHICKEN}

A. JOHNSTON and S. SMOLIAK, Agriculture Canada Research Station, Lethbridge, Alberta T1J 4B 1

Settlement of the western Canadian prairies had a great impact on bird life. Certain species failed to adapt to settlement and disappeared; others changed to conform to the changed environment and survived. Examples are the Turkey Vulture, which is now very scarce or absent from the region, and the Brown-headed Cowbird, which changed from an association with buffalo to an association with cattle.

Population densities of still other species changed radically. One of these was the Greater Prairie Chicken, known also as the pinnated grouse, squaretail or prairie hen. It migrated into the country from Minnesota and North Dakota and its population increased rapidly from 1881 to about 1900 , then declined equally rapidly to very low numbers by 1925 . The last reliable records of the species were a specimen taken near Youngstown, Alberta, in 1938 and another in Saskatchewan in 1943.7" More recent sightings have been reported. $1 \mathrm{x}$

The purpose of this study was to relate the fluctuations in numbers of 